\title{
Development of a Polymer Based Syntactic Foam for High Temperature Applications
}

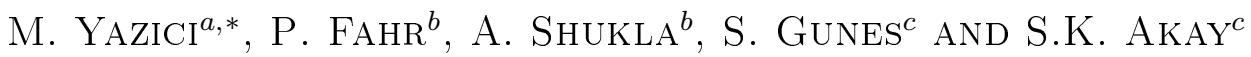 \\ ${ }^{a}$ Uludag University, Eng. Arch. Faculty, Automotive Eng. Dept., 16059 Bursa, Turkey \\ ${ }^{b}$ University of Rhode Island, Dept. of Mech., Ind. and Sys. Eng., Kingston, RI, USA \\ ${ }^{c}$ Uludag University, Faculty of Science and Arts, Department of Physics, 16059 Bursa, Turkey
}

\begin{abstract}
Syntactic foams are one of the most widely used close cell structured foams. They are used in applications for naval, aeronautical, aerospace, civil, industrial, and automotive engineering due to good acoustical attenuation, excellent strength to weight ratio, vibration isolation, and dielectric properties. These foams are fabricated by incorporation of hollow particles in a matrix material. The most preferred matrix materials are polymers. In this study silicone resin (useful temperature range $-53{ }^{\circ} \mathrm{C}$ to $232{ }^{\circ} \mathrm{C}$ ) was selected as a binder material. Glass bubbles were incorporated into the silicone resin at three different mass percentages $(10 \%, 20 \%$, and $30 \%)$. The density of the silicone was reduced more than $50 \%$ by $30 \%$ glass bubble contribution. The foam mechanical properties were investigated in a room temperature and after heat treatment at $500{ }^{\circ} \mathrm{C}$ by quasi-static compression experiments. Microstructural transitions by the temperature raises were examined by using scanning electron microscopy pictures. It was observed that the increase of glass bubble percentage in silicone rubber enhanced the energy absorption properties in the heat treated and room temperature specimens. Plateau stress and densification amount were improved under quasi-static compression load by the glass bubble percentage increase. It can be said that developed syntactic foams can be used in heat resistant, low weight and high compression strength exigencies.
\end{abstract}

DOI: $10.12693 /$ APhysPolA.125.526

PACS: 81.05.Qk, 81.70.Bt, 81.40.-z, 81.05.Lg

\section{Introduction}

Many applications demand the use of light weight materials, but often at the cost of reduced strength. Foams can provide significant weight saving structures but their applications are limited by their low strength and modulus. In recent years considerable efforts have been invested in developing methods of introducing porosity in materials without causing detrimental effects on the mechanical properties of material [1]. Syntactic foams are a class of porous materials in which manufactured by filling a polymeric matrix with hollow spheres called microspheres or microballoons. Syntactic foams are sometimes described as three-phase composites, considering interstitial voids within the matrix to be the third phase $[2,3]$. Compared with standard foams (containing blown gas bubbles only), syntactic foams are often preferred in weight-sensitive applications, for which their enhanced mechanical properties and tailorability make them useful $[4,5]$.

Several compositions of nano scale-reinforced syntactic foams are now developed for further enhancement in mechanical and thermal properties [6, 7]. As a class of advanced lightweight composites, syntactic foams have been widely employed in more and more engineering applications, e.g., marine equipment for deep sea operations [8], aircraft components, spacecraft solid rocket booster nose cone filling, thermal insulation for deep sea pipelines [9-11], core materials of sandwiches [12, 13],

*corresponding author; e-mail: myazici@uludag.edu.tr

and structural components in the aerospace industry [14]. While a wide body of literature is now available on room-temperature mechanical properties of syntactic foams, relatively few efforts are found focused on thermal properties such as coefficient of thermal expansion [15], thermal conductivity $[4,16]$ and high temperature behavior [17]. In spite of the abundant literature regarding various thermoplastic and thermo set resin based syntactic foams, few studies consider silicone rubber based syntactic foams $[18,19]$. According to the authors' investigations, there is no current literature about silicone based high temperature resistive syntactic foams.

In this study, novel high temperature resistive polymer based syntactic foams were developed. Compression properties of the foams are compared with respect to glass bubble percentage variation under high and room temperatures.

\section{Experimental procedure}

High temperature closed cell syntactic foam was produced by using platinum silicone resin and two different type glass bubble contributions at 10,20, 30 weight percentages. A liquid silicone rubber resin $\left(\right.$ MoldStar $\left.^{\circledR} 30\right)$ was used as a matrix material, obtained with mixing two supplied components (A and B) which are mixed 1A:1B by volume. These easy to use platinum silicone features, relatively low viscosities (according to ASTM D2393/12500 cps), and vacuum degassing is not required for most applications. The pot life is $45 \mathrm{~min}$ and cure time is $6 \mathrm{~h}$ at room temperature. MoldStar $30^{\circledR}$ has 30 Shore A hardness. Tensile strength (ASTM D412) is $2.90 \mathrm{MPa}$ and elasticity modulus is $0.66 \mathrm{MPa}$. Cured Mold Star ${ }^{\circledR}$ rubber is heat resistant up to $232{ }^{\circ} \mathrm{C}$ [20]. Closed-cells structure was obtained after reinforcement 
with glass bubbles. Glass bubbles (Fig. 1a) were obtained from 3M Company with the product codes: A16/ 500 and A20/1000. The properties of these bubbles are given in Table I. The glass bubbles are thermally stable up to the $600{ }^{\circ} \mathrm{C}$, depending on temperature and duration of exposure.

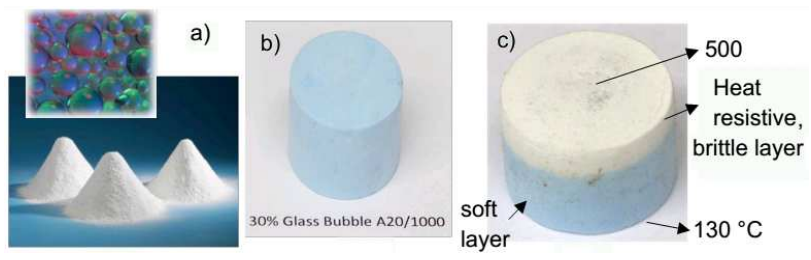

Fig. 1. (a) Glass bubbles, (b) virgin syntactic foam (30\% GB1000), (c) heat treated syntactic foam $(30 \%$ GB1000) and temperature measurement points.

Properties of the glass bubbles [21].

TABLE I

\begin{tabular}{c|c|c|c|c}
\hline \hline & $\begin{array}{c}\text { Test } \\
\text { pressure } \\
{[\mathrm{MPA}]} \\
(\mathrm{PSI})\end{array}$ & $\begin{array}{c}\text { Density } \\
{[\mathrm{g} / \mathrm{cc}]}\end{array}$ & $\begin{array}{c}\text { Particle } \\
\text { size } \\
{[\mu \mathrm{m}]}\end{array}$ & $\begin{array}{c}\text { Thermal } \\
\text { conductivity } \\
{[\mathrm{W} /(\mathrm{m} \mathrm{K})]} \\
\text { at 20 }{ }^{\circ} \mathrm{C}\end{array}$ \\
\hline $\mathrm{A} 16 / 500$ & $3.44(500)$ & 0.16 & 115 & $0.06-0.16$ \\
$\mathrm{~A} 20 / 1000$ & $6.90(1000)$ & 0.20 & 105 & $0.06-0.16$
\end{tabular}

A syntactic foam was produced by mixing silicone rubber and glass bubbles by hand. After mixing for $20 \mathrm{~min}$, the raw material was filled in a wax mold and compressed by hand. The specimen was designed to be cylindrical with a diameter of $25 \mathrm{~mm}$ and a height of $17 \mathrm{~mm}$. High temperature heating of specimens were performed by applying a constant temperature of $500 \pm 10^{\circ} \mathrm{C}$ to one side of the specimen for a duration of one hour. During this time, the specimen's opposite surface was left exposed to ambient temperatures. Temperatures were recorded on both surfaces using thermocouples.

Density of the foams was obtained by using weight measurement with $0.0001 \mathrm{~g}$ sensitive weighing scale and volume calculations. Compression experiments were performed by using Instron 5585 universal testing machine with a $1 \mathrm{~mm} / \mathrm{min}$ cross head speed. Experiments were performed at room temperature for specimens with and without heat treatment. The microstructures were investigated by using a SEM microscope.

\section{Results and discussion}

Syntactic foam densities decreased with the addition of glass bubbles in higher percentages. In syntactic foams containing $30 \%$ glass bubbles by weight, the density decreased $63 \%$ using A20/1000 glass bubbles (henceforth GB1000) and $68 \%$ using A16/500 glass bubbles (henceforth GB500). Room temperature quasi-static experiments were performed on the syntactic foams to ascertain the glass bubbles' weight percentage effect on compression strength and energy absorbing capabilities. The selected glass bubbles have a low failure compression strength, they collapsed during the syntactic foams' compression. Because of this, the foams' stress versus strain plots show more plateau regions, suggesting greater energy absorbing properties.

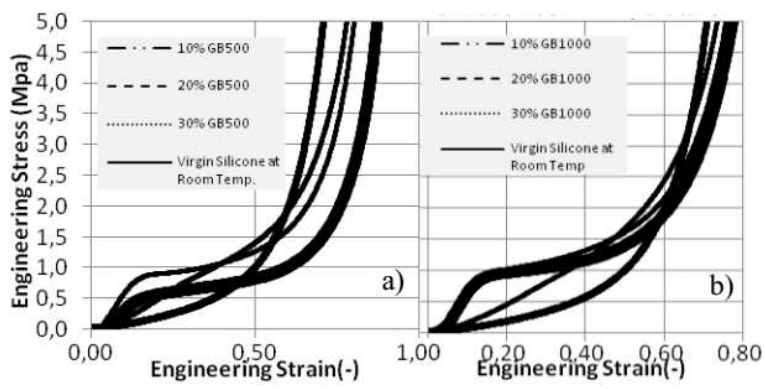

Fig. 2. Quasi static compression variation of the developed syntactic foams at room temperature: (a) GB500 syntactic foam, (b) GB1000 syntactic foam.

Density of the syntactic foams.

TABLE II

\begin{tabular}{c|c|c}
\hline \hline Weight percentage of glass bubbles & \multicolumn{2}{|c}{ Density $\left[\mathrm{kg} / \mathrm{m}^{3}\right]$} \\
\cline { 2 - 3 } & GB500 & GB1000 \\
\hline $10 \%$ & 739.78 & 747.95 \\
$20 \%$ & 472.25 & 539.57 \\
$30 \%$ & 360.38 & 409.61 \\
\hline \multicolumn{2}{c}{ silicone rubber resin } & 1120
\end{tabular}

The variations of the quasi-static compression behavior are given in Fig. 2 for GB500 and GB1000 syntactic foams. It is observed that in Fig. 2 the virgin silicone rubber behaves as a viscoelastic material and that the introduction of glass bubbles increases the plateau stress of the material. Figure $2 \mathrm{a}$ and $\mathrm{b}$ shows the results of compression tests between the two syntactic foams, GB500 and GB1000, with the different glass bubbles with their respective crush strengths: the A16/500 (3.44 MPa) and A20/1000 (6.90 MPa) glass bubbles.

The specimens that were heated (at constant $500^{\circ} \mathrm{C}$ ) were originally light blue in color. The color, originating from the heated surface, started to change white and after about $20 \mathrm{~min}$, stabilized at less than $1 / 3$ of the specimens section height (Fig. 1b). During heating, the face expose to ambient temperature was measured, and a steady state surface temperature of $130^{\circ} \mathrm{C}$ was obtained. When heated to $500^{\circ} \mathrm{C}$, the glass bubbles remain intact within the syntactic foam (Fig. 3a). Because of maximum temperature sensitivity of the glass bubble is around $600{ }^{\circ} \mathrm{C}$, any heating beyond this temperature, the glass bubbles would rupture (Fig. 3b). For these purpose in this study, heating is limited to $500{ }^{\circ} \mathrm{C}$. The white section is more brittle and heat resistive than the virgin syntactic foam. After heating, the foam developed into a two layered foam structure. The front layer (heat treated surface) is brittle and heat resistive (Fig. 1c), while the back layer exhibits more elastic and plastic properties similar to the unheated syntactic foams (Fig. 1b).

In Fig. 4 the high temperature heat treated specimens quasi-static compression results are given. It was ob- 


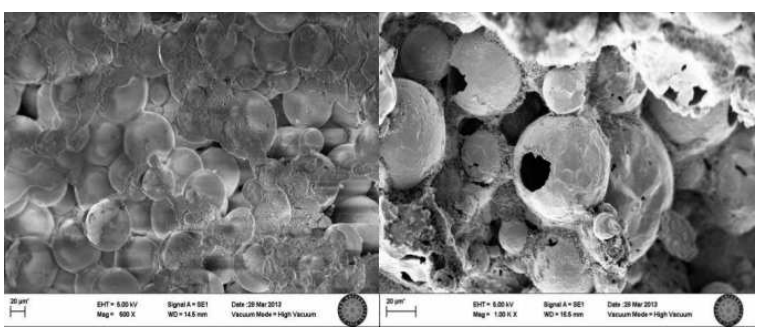

Fig. 3. (a) $500{ }^{\circ} \mathrm{C}$ heat treated $30 \%$ GB1000 syntactic foam $500 \times \mathrm{SEM}$ picture, (b) $750{ }^{\circ} \mathrm{C}$ heat treated $30 \%$ GB 1000 syntactic foam $1000 \times$ SEM picture.

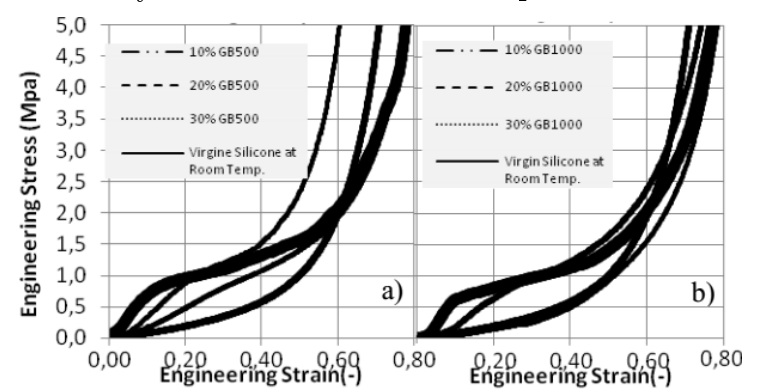

Fig. 4. Plots of stress-strain variation from quasi-static compression of the developed syntactic foams after hightemperature heat treatment a) GB500 syntactic foam b) GB1000 syntactic foam.

served that plateau stress and plateau region sizes are dependent on glass bubbles weight percentage.

Figures 2 and 4 show that heating the specimens, from one face, does not affect the compression properties considerably of the developed syntactic foam.

\section{Conclusions}

In this study, high temperature resistive silicone based syntactic foams were developed. The effect of post high temperature heating on material properties were investigated using quasi-static compression tests. Results obtained can be summarized as follows: (1) a high temperature resistive layer forms when the silicone syntactic foam is subjected to heating on one surface, (2) foam is transformed to a two layer structure during high temperature heating (brittle and soft layers), (3) the foam shows very good heat resistivity with the brittle layer working as a heat barrier, (4) compression strength properties were not affected after heating processes, (5) the insulative properties of silicone rubber improved with higher weight percentages of glass bubbles, (6) the introduction of glass bubbles lowers the density of silicone rubber, (7) during compression tests, the plateau (crush) regions improved by introducing higher amounts of glass bubbles. This means that energy absorbing capability was increased.

\section{Acknowledgments}

The authors acknowledge the financial support provided by $3 \mathrm{M}$ Ind. \& Transp. Business En. \& Adv. Mat. Div. Murat Yazici acknowledges the financial support of the TUBITAK 2219 Int. Post Doc. Research Fellowship Program.

\section{References}

[1] N. Gupta, V.C. Shunmugasamy, Mater. Sci. Eng. A 528, 7596 (2011).

[2] V. Shabde, K. Hoo, G. Gladysz, J. Mater. Sci. 41, 4061 (2006).

[3] G. Gladysz, B. Perry, G. McEachen, J. Lula, J. Mater. Sci. 41, 4085 (2006).

[4] N. Gupta, E. Woldesenbet, P. Mensah, A. Compos. Appl. Sci. Manuf. 35, 103 (2004).

[5] N. Gupta, K. Kishore, E. Woldesenbet, S. Sankaran, J. Mater. Sci. 36, 4485 (2001).

[6] R. Poveda, S. Achar, N. Gupta, JOM J. Miner. Met. Mater. Soc. 64, 1148 (2012).

[7] M. Dimchev, R. Caeti, N. Gupta, Mater. Des. 31, 1332 (2010)

[8] V.T. Phan, D. Choqueuse, J.Y. Cognard, L. Sohier, Prog. Org. Coat. 76, 341 (2013).

[9] C.I. Stuckey, T.R. Reinarts, D. Davis, AIP Conf. Proc. 552, 98 (2001).

[10] F. Grosjean, N. Bouchonneau, D. Choqueuse, V. Sauvant-Moynot, J. Mater. Sci. 44, 1462 (2009).

[11] N. Bouchonneau, V. Sauvant-Moynot, D. Choqueuse, F. Grosjean, E. Poncet, D. Perreux, J. Petrol. Sci. Eng. 73, 1 (2010).

[12] A. Corigliano, E. Rizzi, E. Papa, Compos. Sci. Technol. 60, 2169 (2000).

[13] L. Bardella, F. Genna, Int. J. Solids Struct. 38, 307 (2001).

[14] E.S. Weiser, T.F. Johnson, T.L.S. Clair, Y. Echigo, H. Kaneshiro, High Perform. Polym. 12, 1 (2000).

[15] V. Shunmugasamy, D. Pinisetty, N. Gupta, J. Mater. Sci. 47, 5596 (2012).

[16] M. Porfiri, N. Nguyen, N. Gupta, J. Mater. Sci. 44, 1540 (2009).

[17] T. Lin, N. Gupta, A. Talalayev, J. Mater. Sci. 44 , 1520 (2009).

[18] T. Muthukumar, A. Aravinthan, K. Lakshmi, R. Enkatesan, L. Vedaprakash, M. Doble, Int. Biodeterior. Biodegrad. 65, 76 (2011).

[19] M. Kessler, A. Schnettler, IEEE Trans. Dielectr. Electr. Insul. 17, 898 (2010).

[20] http://ww. smooth-on.com/Silicone-Rubber-an/ c2/index.html.

[21] http://www.3M.com/oilandgas . 